\title{
Senam Jantung Sehat Seri-I Tiga kali seminggu Meningkatkan Kebugaran Jasmani Lansia
}

\author{
Nita Fitria ${ }^{1^{*}}$, Lynna Lidyana ${ }^{2}$, Shelly Iskandar $^{3}$, Leonardo Lubis $^{4}$, Ambrosius Purba $^{5}$ \\ ${ }^{1}$ Departemen Keperawatan Dasar, Fakultas Keperawatan, UNPAD, Bandung, Indonesia \\ ${ }^{2,3}$ Departemen Kedokteran Jiwa, Fakultas Kedokteran, UNPAD, Bandung, Indonesia \\ ${ }^{4,5}$ Departemen Anatomi Fisiologi, Fakultas Kedokteran, UNPAD, Bandung, Indonesia \\ *Email korespondensi: nita.fitria@unpad.ac.id
}

\begin{abstract}
ARTICLE INFO
\section{HOW TO CITED:}

Fitria, N., Lidyana, L., Iskandar, S., Lubis, L., dan Purba, A. (2019). Senam Jantung Sehat Seri-I Tiga kali seminggu Meningkatkan Kebugaran Jasmani Lansia. Jurnal Pendidikan Keperawatan Indonesia 5(1), p. 51-66
\end{abstract}

DOI:

10.17509/jpki.v5i1.15741

ARTICLE HISTORY:
Accepted
April 23, 2019
Revised
May 02, 2019
Published
June 30,2019

\section{A B S T R A K}

Penurunan kebugaran jasmani berkontribusi terhadap angka kesakitan dan kematian lansia. Salah satu pengukuran kebugaran jasmani seseorang yang berusia $>60$ tahun dapat ditentukan melalui tes jalan enam menit (six minutes test). Upaya untuk meningkatkan derajat kebugaran jasmani diperlukan olahraga salah satunya Senam Jantung Sehat Seri-I yang memperhatikan frekuensi latihan yang tepat. Tujuan dari penelitian ini adalah untuk menganalisis frekuensi Senam jantung Sehat Seri-I yang dapat meningkatkan kebugaran jasmani pada lansia. Penelitian ini menggunakan metode preexperimental dengan pendekatan pre-test dan post-test design yang mengikutsertakan 27 lansia sehat dan rutin melakukan senam Jantung Sehat Seri-I yang tinggal di Panti Whreda. Subjek penelitian terbagi menjadi tiga kelompok berdasarkan frekuensi aktivitas senam per minggu yaitu 3,4, dan 5 kali seminggu selama enam minggu. Peningkatan kebugaran jasmani ditentukan melalui jarak tempuh yang dilalui lansia setelah tes jalan enam menit (six minutes test) pada minggu ke-1 dan ke-6. Perbedaan rata-rata jarak tempuh setelah dilakukan senam secara statistik dianalis menggunakan uji-t berpasanan dengan $\mathrm{p}$-value $<0,05$ dinyatakan sebagai signifikan. Berdasarkan hasil penelitian menunjukkan kelompok lansia yang melakukan Senam Jantung Sehat Seri-I 3 kali seminggu memiliki rata-rata perbedaan jarak tempuh yang signifikan (mean difference $=-106,0 ; \mathrm{p}=0,009$ ), sementara kelompok 4 dan 5 kali seminggu tidak menunjukkan hasil yang signifikan. Penelitian ini memberikan bukti bahwa Senam Jantung Sehat Seri-I 3 kali seminggu meningkatkan kebugaran jasmani. Peneliti menyarankan kepada Kepala Panti untuk memprogramkan pelaksanaan Senam Jantung Sehat Seri-I frekuensi tiga kali seminggu kepada lansia sehat yang tinggal di panti.

Kata kunci: Kebugaran jasmani lansia, Senam Jantung Sehat Seri-I tiga kali seminggu.

\section{A B S T R A C T}

Decreasing physical fitness contributes to the morbidity and mortality rates of the elderly. The physical fitness level of a person aged $>60$ years is determined through a six minutes test. Efforts to improve physical fitness levels are needed for sports, one of which is Senam Jantung Sehat Seri-I, which takes into account the frequency of exercise. The purpose of this study was to analyze the frequency of Senam Jantung Sehat Seri-I that can improve cardiorespiratory 
fitness in the elderly. This study used a pre-experimental method with a pre-test and post-test design approach that included 27 healthy elderly people and routinely carried out Senam Jantung Sehat SeriI exercises at the Nursing Home. The research subjects were divided into three groups based on the frequency of gymnastics activity per week, which was 3.4, and five times a week for six weeks. Improved physical fitness was determined through the distance traveled on the 6-minute test at the first and sixth weeks. The difference in statistically traveled distance was analyzed using Independent t-test with a p-value $<0.05$ expressed as significant. The elderly group who did Senam Jantung Sehat Seri-I three times a week had a significant mean difference (-106.0; $p=0.009)$, while groups 4 and five times a week did not show significant results. This study showed that Senam Jantung Sehat Seri-I three times a week improves cardiorespiratory fitness.

Keywords: Cardiorespiratory fitness, elderly, Senam Jantung Sehat Seri-I three times a weeks

\section{PENDAHULUAN}

Kemenkes Republik Indonesia (2016) mengatakan prevalensi lanjut usia (lansia) diatas 60 tahun di dunia sejak tahun 2013 mengalami peningkatan. Martinson dan Berridge (2015) menjelaskan peningkatan prevalensi lansia menimbulkan berbagai permasalahan fisik dan psikologis oleh karena lansia mengalami penurunan secara fisiologis dan psikologis. Proses penurunan fisiologis dan psikologis tersebut menyebabkan lansia sulit untuk melakukan aktivitas fisik sehari-hari secara mandiri dan tergantung pada orang lain. Keterbatasan dalam melakukan aktivitas fisik sehari-hari dapat menimbulkan penyakit degeneratif, ketidakmampuan fisik, gangguan rasa nyeri, penurunan fungsi kognitif, gangguan tidur, isolasi sosial. Keterbatasan lansia dalam melakukan aktivitas fisik sehari-hari menyebabkan lansia sulit beradaptasi dalam kondisi proses penuaan, merasa sendiri, frustasi, dan kehilangan kepercayaan diri sehingga timbul depresi yang mempengaruhi kualitas hidup lansia.

Seiring dengan bertambahnya usia lansia ditemukan adanya penurunan derajat kebugaran jasmani. Penurunan derajat kebugaran jasmani usia 70 tahun sekitar 30-50\% (Chung, Baguet, Bex, Bishop, \& Derave, 2014). Penurunan derajat kebugaran jasmani pada lansia disebabkan penurunan fungsi organ tubuh. (GorskaCiebiada, Saryusz-Wolska, Borkowska, \& Loba, 2015). Penurunan derajat kebudayaan jasmani selain disebabkan karena penurunan fungsi organ tubuh, (Gorska-Ciebiada, Saryusz-Wolska,
Borkowska, \& Loba, 2015). Penurunan derajat kebudayaan jasmani selain disebabkan karena penurunan fungsi organ tubuh, pengaruh budaya masyarakat Indonesia yang membatasi aktivitas fisik sehari-hari lansia memberikan andil terhadap penurunan derajat kebugaran jasmani lansia.

Upaya untuk meningkatkan kebugaran jasmani lansia diperlukan aktivitas fisik/olahraga yang aman dan tepat bagi lansia. Agar olahraga yang dilakukan lansia dapat meningkatkan kebugaran jasmani lansia sebaiknya memperhatikan konsep Frequency, Intensity, Time, Type (FITT). Frequency artinya jumlah latihan yang dilakukan setiap minggu, Intensity artinya takaran latihan, Time artinya waktu pelaksanakan setiap latihan, Type artinya jenis latihan (American College of Sports Medicine, 2015).

Kebugaran jasmani erat kaitannya dengan peningkatan daya tahan jantungparu. Untuk meningkatkan daya tahan jantungparu, lansia dapat melakukan latihan $3-5 \mathrm{kali} /$ minggu dengan intensitas latihan ringan dan sedang (intensitas ringan: 50-60\% Denyut Nadi Maksimal (DNM), intensitas sedang 60-75\% DNM. Waktu yang diperlukan setiap melaksanakan latihan selama 20-60 menit/latihan dengan tipe latihan aerobik. Hasil latihan akan meningkatkan daya tahan jantungparu setelah berolahraga selama 6-12 minggu dan stabil setelah 20 minggu (Pescatello, Arena, Riebe, Thomson, Willian, \& Wilkins, 2014). 
Fitria, N., Lidyana, L., Iskandar, S., Lubis, L., dan Purba, A. | Senam Jantung Sehat Seri-I Tiga kali seminggu meningkatkan ...

Ginting (2011)mengatakan Senam Jantung Sehat Seri-I merupakan salah satu olahraga yang dapat dilakukan oleh lansia. Senam Jantung Sehat Seri-I terdiri dari Seri-I sampai Seri-IV dan dipromosikan oleh Yayasan Jantung Indonesia. Senam Jantung Sehat Seri-I memiliki ciri khas gerakan yang teratur dan irama yang lambat serta intensitas latihan yang relatif ringan dan sedang sehingga dapat dilakukan oleh lansia. Senam Jantung Sehat Seri-I diprogramkan untuk mencegah dan rehabilitasi penderita penyakit jantung dan pembuluh darah. Sampai saat ini penelitian mengenai Senam Jantung Sehat terbatas pada pengaruh Senam Jantung Sehat terhadap penurunan tekanan darah sehingga penelitian ini merupakan penelitian baru untuk menganalisis frekuensi Senam Jantung Sehat Seri-I terhadap kebugaran jasmani.

Senam Jantung Sehat Seri-I merupakan olahraga aerobik dengan intensitas sedang dan pelaksanaannya berlangsung selama 30 menit (Ginting,2011). Agar intensitas senam terukur, pelaksanaan Senam Jantung Sehat Seri-I menggunakan alat bantu polar dan pengukuran derajat kebugaran jasmani lansia dilakukan tes jalan enam menit (six minutes test) (Wevers \& Kwakkel, 2011).

Agar konsep FITT dapat diaplikasikan pada Senam Jantung Sehat Seri- I, perlu dilakukan penelitian mengenai frekuensi latihan yang tepat oleh karena itu penelitian ini bertujuan untuk menganalisis "Frekuensi latihan Senam Jantung Sehat Seri-I yang dapat meningkatkan Kebugaran Jasmani Lansia"

\section{METODE}

\section{Desain Penelitian}

Rancangan penelitian ini menggunakan metode pre-experimental dengan pendekatan pretest dan post-test design. Pemilihan preexperimental karena dalam penelitian ini tidak ada kelompok kontrol. Sumber data berasal dari Perlindungan Sosial Rehabilitasi Lanjut Usia (PRSLU) dan Perlindungan Makam Pahlawan (PMP) Unit Pelaksanan Teknis Daerah (UPTD) Ciparay.

Penelitian ini sudah mendapat persetujuan dari Komite Etik Penelitan Universi- tas Padjadjaran no. 0518020297 dengan no surat : 238/UN.6.KEP/EC/2018.

\section{Populasi dan Sampel}

Populasi sasaran adalah semua lansia yang tinggal di PRSLU dan PMP UPTD Ciparay. Jumlah total populasi sasaran adalah 150 orang lansia. Populasi terjangkau adalah lansia sehat berusia $>60$ tahun yang tinggal PRSLU dan PMP UPTD Ciparay Bandung, tidak dalam perawatan rawat inap dan rutin melakukan senam yang telah diprogramkan, intensitas latihan saat melakukan Senam Jantung Sehat Seri-I adalah sedang (60-75\% DNM). Jumlah sampel menggunakan teknik purposive sampling sehingga didapatkan sebanyak 30 lansia. Pada saat penelitian, dua orang lansia sakit dan satu orang pulang dari panti sehingga sampel akhir penelitian berjumlah 27 orang.

\section{Teknik Pengumpulan Data}

Cara Kerja dan teknik pengumpulan data diawali dengan penjelasan secara verbal dan tertulis (informed consent) kepada lansia dibantu oleh pengampu/wali lansia. Apabila lansia telah menyetujui prosedur penelitian, dilakukan penandatanganan lembar persetujuan. Peneliti kemudian melakukan wawancara untuk mengetahui informasi dan konfirmasi data demografi lansia yang terdiri dari usia,jenis kelamin, pendidikan terakhir, riwayat penyakit penyerta, riwayat medik/obat-obatan, lamanya tinggal di panti.

Penelitian dimulai dengan pemilihan lansia sehat yang tinggal di PSRLU dan PMP UPTD Ciparay berdasarkan teknik purposive sampling. Setelah lansia sehat menandatangani informed consent dilakukan pengukuran DNM setiap individu berdasarkan rumus: $60-75 \%$ (220-usia) sehingga didapatkan rentang nilai minimal dan nilai maksimal DNM. Apabila saat Senam Jantung Sehat Seri-I DNM lansia dibawah nilai minimal dan diatas nilai maksimal maka tidak diambil menjadi sampel. Setelah ditentukan rentang nilai minimal dan nilai maksimal DNM, dilakukan pengumpulan data rerata nilai denyut nadi latihan selama melakukan Senam Jantung Sehat Seri-I. 
Fitria, N., Lidyana, L., Iskandar, S., Lubis, L., dan Purba, A. | Senam Jantung Sehat Seri-I Tiga kali seminggu meningkatkan ...

Tabel 1. Judul Karakteristik Lansia berdasarkan usia, jenis kelamin dan pendidikan terakhir $(\mathbf{n}=\mathbf{3 0})$

\begin{tabular}{lcc}
\hline \multicolumn{1}{c}{ Karakteristik } & Frekuensi (f) & Persentase (\%) \\
\hline Usia & 23 & 76,67 \\
Elderly (60-74) & 6 & 20,00 \\
Old (75-90) & & \\
& 15 & \\
Jenis Kelamin & & 50,00 \\
Laki-laki & & \\
& 6 & \\
Pendidikan Terakhir & 7 & 20,00 \\
Tidak sekolah & 6 & 23,00 \\
SD & 6 & 20,00 \\
SMP & & 20,0 \\
SMA & & \\
\hline
\end{tabular}

Setelah lansia melakukan Senam, ditentukan intensitas latihan (ringan, sedang, berat) yang dirasakan peserta. Intensitas latihan yang diambil adalah intensitas sedang agar memberikan mencapai efek positif dari latihan, sedangkan internsitas ringan dan berat tidak dimasukkan dalam sampel.

Kelompok lansia yang memiliki intensitasnya sedang kemudian dibagi kedalam 3 kelompok yaitu lansia yang melakukan Senam Jantung Sehat Seri-I dengan frekuensi 3 kali seminggu, 4 kali seminggu dan 5 kali seminggu sehingga dapat dianalisis frekuensi yang tepat untuk meningkatkan kebugaran jasmani pada lansia.

Ketiga kelompok dilakukan tes jalan 6 menit untuk mengukur jarak tempuh (m) yang dapat dilakukan lansia saat berjalan. Pengukuran derajat kebugaran jasmani tersebut dilakukan sebelum Senam Jantung Sehat Seri-I dan minggu ke6 setelah senam.

\section{Analisa Data}

Rancangan analisis data penelitian diproses dengan menggunakan IBM SPSS versi 23.0
Sebelum data dianalis dilakukan uji uji normalitas Shapiro-Wilk $(\mathrm{p} \geq 0,05)$ dan uji homogenitas One way ANOVA $(p \geq 0,05)$. Hasil uji normalitas semua variabel : usia, jenis kelamin, pendidikan terakhir, Denyut Nadi Maksimal, Denyut Nadi Istirahat ,Tinggi Badan, Berat Badan, Tekanan Darah Sistolik, Tekanan Darah Diastolik dalam batas normal dan nilai derajat kebugaran jasmani sebelum Senam Jantung SehatSeri-I (pre) adalah homogen $(p \geq 0,05)$.

Hasil uji homogenitas dilakukan untuk menentukan apakah data sebelum diberikan perlakuan Senam Jantung Sehat Seri-I (pre) dapat dijadikan sebagai pedoman untuk melihat ada tidaknya efek intervensi terhadap kebugaran jasmani (daya tahan jantungparu). Untuk menganalisis perbedaan kebugaran jasmani sebelum dilakukan senam dan setelah mengikuti senam Jantung Sehat Seri-I pada minggu ke-6 menggunakan uji-t berpasangan.

\section{HASIL}

\section{Karakteristik Subjek Penelitian}

Karakteristik subjek penelitian meliputi data usia, jenis kelamin, pendidikan terakhir. Tabel 1 
Fitria, N., Lidyana, L., Iskandar, S., Lubis, L., dan Purba, A. I Senam Jantung Sehat Seri-I Tiga kali seminggu meningkatkan ...

Tabel 2. Karakteristik Lansia berdasarkan Frekuensi Senam (n=27)

\begin{tabular}{|c|c|c|c|c|c|}
\hline Karakteristik & Frekuensi Senam & $\mathrm{n}$ & mean $+\mathrm{SD}$ & P-value & Keterangan \\
\hline Denyut Nadi & 3 kali seminggu & 10 & $84,1 \pm 7,18$ & 0,515 & Normal \\
\hline \multirow{2}{*}{ Maksimal } & 4 kali seminggu & 9 & $72,89 \pm 8,19$ & 0,063 & Normal \\
\hline & 5 kali seminggu & 8 & $72,5 \pm 7,54$ & 0,137 & Normal \\
\hline Denyut Nadi & 3 kali seminggu & 10 & $83,9 \pm 6,97$ & 0,740 & Normal \\
\hline \multirow{3}{*}{ Istirahat } & 4 kali seminggu & 9 & $72,89 \pm 8,19$ & 0,063 & Normal \\
\hline & 5 kali seminggu & 8 & $72,5 \pm 7,54$ & 0,137 & Normal \\
\hline & 3 kali seminggu & 10 & $146,0 \pm 10,73$ & 0,377 & Normal \\
\hline \multirow{3}{*}{ Tinggi Badan } & 4 kali seminggu & 9 & $151,39 \pm 15,29$ & 0,523 & Normal \\
\hline & 5 kali seminggu & 8 & $150,75 \pm 10,01$ & 0,976 & Normal \\
\hline & 3 kali seminggu & 10 & $47,0 \pm 6,53$ & 0,113 & Normal \\
\hline \multirow[t]{3}{*}{ Berat Badan } & 4 kali seminggu & 9 & $54,44 \pm 13,05$ & 0,168 & Normal \\
\hline & 5 kali seminggu & 8 & $46,25 \pm 9,6$ & 0,679 & Normal \\
\hline & 3 kali seminggu & 10 & $156,6 \pm 26,49$ & 0,482 & Normal \\
\hline \multirow[t]{2}{*}{ Tekanan Darah } & 4 kali seminggu & 9 & $143,11 \pm 16,94$ & 0,731 & Normal \\
\hline & 5 kali seminggu & 8 & $154,13 \pm 28,01$ & 0,471 & Normal \\
\hline \multirow{3}{*}{$\begin{array}{c}\text { Tekanan Darah } \\
\text { Diastolik }\end{array}$} & 3 kali seminggu & 10 & $87,4 \pm 14,33$ & 0,207 & Normal \\
\hline & 4 kali seminggu & 9 & $80,0 \pm 14,14$ & 0,327 & Normal \\
\hline & 5 kali seminggu & 8 & $82,0 \pm 18,14$ & 0,541 & Normal \\
\hline
\end{tabular}

Tabel 3. Nilai Minimal dan Maksimal Denyut Nadi Maksimum (DNM) Lansia (n=27)

\begin{tabular}{ccc}
\hline Prosentase DNM & Nilai minimum & Nilai maksimum \\
\hline $60 \%$ & 77,4 & 96,75 \\
$75 \%$ & 95,4 & 119,25 \\
\hline
\end{tabular}


Fitria, N., Lidyana, L., Iskandar, S., Lubis, L., dan Purba, A. | Senam Jantung Sehat Seri-I Tiga kali seminggu meningkatkan ...

Tabel 4. Perbedaan rerata sebelum dan setelah melakukan Senam Jantung Sehat Seri-I terhadap kebugaran jasmani (daya tahan jantung paru) $(n=27)$

\begin{tabular}{|c|c|c|c|c|c|}
\hline $\begin{array}{c}\text { Variabel } \\
\text { Independen }\end{array}$ & Mean & Std. Deviation & $\begin{array}{c}\text { Mean } \\
\text { difference }\end{array}$ & $\mathrm{t}$ & p-value \\
\hline $\begin{array}{l}\text { kebugaran jasmani } \\
\text { (pre-intervensi) }\end{array}$ & 314,77 & 109,12 & \multirow{2}{*}{$-52,26$} & $-2,346$ & 0,027 \\
\hline $\begin{array}{l}\text { kebugaran jasmani } \\
\text { (post-intervensi) }\end{array}$ & 367,03 & 101,65 & & & \\
\hline
\end{tabular}

Tabel 5. Perbedaan Rerata Frekuensi Senam Jantung Sehat Seri-I menggunakan uji Post-Hoc

\begin{tabular}{ccccc}
\hline \multirow{2}{*}{ Frekuensi Senam } & \multirow{2}{*}{$\begin{array}{c}\text { Mean } \\
\text { Difference }\end{array}$} & Minimum & Maksimum & \multirow{2}{*}{ p-value } \\
\cline { 3 - 4 } & $-65,17$ & $-224,25$ & 93,89 & 0,906 \\
\hline 3 kali vs 4 kali seminggu & $-171,09$ & $-335,32$ & $-6,87$ & 0,039 \\
3 kali vs 5 kali seminggu & $-105,92$ & $-274,15$ & 62,30 & 0,355 \\
4 kali vs 5 kali seminggu & & & \\
\hline
\end{tabular}

Tabel 6. Perbedaan Rerata nilai kebugaran jasmani sebelum dan setelah senam berdasarkan Frekuensi Senam $(n=27)$

\begin{tabular}{lllcccc}
\hline Frekuensi Senam & Variabel Independen & Mean & $\begin{array}{c}\text { Std. Devia- } \\
\text { tion }\end{array}$ & $\begin{array}{c}\text { Mean } \\
\text { difference }\end{array}$ & t & p-Value \\
\hline 3 kali seminggu & $\begin{array}{l}\text { kebugaran jasmani } \\
\text { (pre-intervensi) }\end{array}$ & 269,5 & 102,5 & $-106,0$ & $-3,348$ & 0,009 \\
& $\begin{array}{l}\text { kebugaran jasmani } \\
\text { (post-intervensi) }\end{array}$ & 375,5 & 79,98 & & & \\
4 kali seminggu & $\begin{array}{l}\text { kebugaran jasmani } \\
\text { (pre-intervensi) }\end{array}$ & 323,22 & 104,62 & 3,33 & 0,138 & 0,894 \\
& $\begin{array}{l}\text { kebugaran jasmani } \\
\text { (post-intervensi) }\end{array}$ & 319,89 & 132,88 & & & \\
5 kali seminggu & $\begin{array}{l}\text { kebugaran jasmani } \\
\text { (pre-intervensi) }\end{array}$ & 361,87 & 112,46 & $-47,63$ & $-0,893$ & 0,402 \\
& $\begin{array}{l}\text { kebugaran jasmani } \\
\text { (post-intervensi) }\end{array}$ & 409,50 & 70,36 & & & \\
\hline
\end{tabular}

menunjukkan bahwa lebih dari setengahnya lansia berada pada kelompok lansia elderly (60-74 tahun), setengah dari lansia berjenis kelamin laki-laki dan perempuan. Berdasarkan pendidikan terakhir, sebagian kecil lansia merupakan lulusan SD.
Karakteristik subjek penelitian meliputi Denyut Nadi Maksimal (x/mnt), Denyut Nadi Istirahat (x/mnt), Tinggi Badan (cm), Berat Badan (kg), Tekanan Darah Sistolik (mmHg), Tekanan Darah Diastolik (mmHg) berdasarkan frekuensi senam di PSRLU dan PMP UPTD Ci- 
Fitria, N., Lidyana, L., Iskandar, S., Lubis, L., dan Purba, A. I Senam Jantung Sehat Seri-I Tiga kali seminggu meningkatkan ...

Ciparay Provinsi Jawa Barat $(\mathrm{n}=27)$ tercantum pada Tabel 2.

Tabel 2 menunjukkan Denyut Nadi Maksimal, Denyut Nadi Istirahat, Tinggi Badan, Berat Badan, Tekanan Darah Sistolik, Tekanan Darah Diastolik berdasarkan ketiga frekuensi latihan dalam batas normal. menggunakan uji-t berpasangan.

Intensitas yang tepat bagi lansia sehat untuk meningkatkan kebugaran jasmani jantung paru

Untuk melihat intensitas latihan Senam Jantung Sehat Seri-I yang tepat bagi lansia sehat dapat dilihat dari rumus DNM: 60\%-75\% (220usia). Tabel 3 menampilkan nilai minimum dan nilai maksimum DNM lansia.

Berdasarkan tabel 5 menunjukkan rentang nilai DNM lansia : 77,4-119,25 x/menit. Nilai tersebut berada pada intensitas sedang bagi lansia.

Frekuensi Senam Jantung Sehat Seri-I yang tepat bagi lansia sehat untuk meningkatkan kebugaran jasmani (daya tahan jantung paru)

Untuk mengetahui frekuensi Senam Jantung Sehat Seri-I yang tepat bagi lansia sehat untuk meningkatkan kebugaran jasmani diperlukan uji$\mathrm{t}$ berpasangan (paired t-test) sehingga dapat ditentukan adanya perbedaan rerata sebelum dan setelah melakukan Senam Jantung Sehat Seri-I terhadap kebugaran jasmani (daya tahan jantungparu). Perbedaan rerata sebelum dan setelah melakukan Senam Jantung Sehat Seri-I terhadap kebugaran jasmani (daya tahan jantungparu) berdasarkan pengukuran tes jalan enam menit (six minutes test) tercantum pada tabel 4.

Berdasarkan tabel 4 menunjukkan nilai kebugaran jasmani lansia mempunyai perbedaan rerata sebelum dan setelah senam (mean difference) sebesar -52,26 yang berarti terjadi kenaikan kebugaran jasmani lansia sebelum dengan setelah Senam Jantung Sehat Seri I ( p-value = $0,027, \mathrm{p}<0,05)$.

Untuk menentukan frekuensi Senam Jantung Sehat seri-I yang terbaik dilakukan uji-t ( $p$ $<0,05$ ) post intervensi yang tercantum pada table 5 kemudian dilanjutkan dengan uji Post Hoc (Bonferoni) $(\mathrm{p}<0,05)$ untuk mencari perbedaan rerata frekuensi Senam Jantung Sehat SeriI. Hasil uji Post Hoc tercantum pada tabel 5.

Berdasarkan tabel 5 menunjukkan adanya perbedaan nilai pada frekuensi Senam Jantung Sehat Seri-I tiga kali seminggu dengan lima kali seminggu $(\mathrm{p}$-value $=0,039, \mathrm{p}<0,05)$ sedangkan frekuensi senam $3 x$ seminggu dengan empat kali seminggu serta frekuensi senam es New Roman

kali seminggu dengan lima kali seminggu tidak terdapat perbedaan ( $\mathrm{p}$-value $=0,906, p$ $>0,05$ dan $p$-value $=0,355, \mathrm{p}>0,05)$.

Untuk menentukan frekuensi Senam Jantung Sehat Seri-I yang tepat maka dapat dilihat dari perbedaan rata-rata nilai kebugaran jasmani (daya tahan jantung paru) yang tercantum pada tabel 6 .

Tabel 6 menunjukkan Senam Jantung Sehat Seri-I yang dilakukan dengan frekuensi tiga kali seminggu akan meningkatkan kebugaran jasmani pada lansia sehat sebesar $139,33 \%$ (mean difference $=-106$ dan $p$-value $=0,009, p<0,05)$. Hasil uji menunjukkan Senam Jantung Sehat Seri-I yang dilakukan dengan frekuensi 4 kali seminggu akan menurunkan kebugaran jasmani pada lansia sehat sebesar $98,96 \%$ (mean difference $=3,33$ dan $p$-value $=0,894, p<0,05)$. Hasil uji menunjukkan Senam Jantung Sehat Seri-I yang dilakukan dengan frekuensi lima kali seminggu akan meningkatkan kebugaran jasmani pada lansia sehat sebesar 113,16\% (mean difference $=-47,63$ dan $p$-value $=0,402, p<$ 0,05). Walaupun Senam Jantung Sehat Seri-I yang dilakukan dengan frekuensi lima kali minggu akan meningkatkan kebugaran jasmani, namun $p$-value nya tidak signifikan $(\mathrm{p}>0,05)$ sehingga tidak dapat dijadikan sebagai standar hasil. Dari tabel 8 tersebut dapat disimpulkan bahwa Senam Jantung Sehat Seri-I frekuensi tiga kali seminggu lebih tepat dibandingkan empat kali seminggu atau lima kali seminggu dalam meningkatkan kebugaran jasmani (daya tahan jantungparu). 
Fitria, N., Lidyana, L., Iskandar, S., Lubis, L., dan Purba, A. | Senam Jantung Sehat Seri-I Tiga kali seminggu meningkatkan ...

\section{PEMBAHASAN}

Tabel 8 menunjukkan Senam Jantung Sehat Seri-I yang dilakukan dengan frekuensi tiga kali minggu akan meningkatkan kebugaran jasmani pada lansia sehat dibandingkan frekuensi empat kali minggu dan frekuensi lima kali seminggu.

Derajat kebugaran jasmani pada lansia menggambarkan daya tahan jantungparu seseorang. Daya tahan jantungparu disebut juga daya tahan aerobik atau kapasitas aerobik. Kebugaran jasmani menggambarkan kemampuan dan kesanggupan melakukan pekerjaan dalam waktu yang relatif lama tanpa menimbulkan kelelahan yang berlebihan (Chung, Baguet, Bex, Bishop, \& Derave, 2014).

Bertambahnya usia lansia menyebabkan penurunan derajat kebugaran jasmani sekitar 30$50 \%$ pada usia 70 tahun. Lansia akan mengalami penurunan kebugaran jasmani oleh karena terjadinya penurunan kemampuan paru menangkap oksigen, kemampuan hemoglobin mengikat oksigen, kemampuan jantung dalam memompa darah keseluruh tubuh dan kemampuan mioglobin otot menangkap oksigen (Chung, Baguet, Bex, Bishop, \& Derave, 2014).

Penelitian terhadap 95 orang lansia ratarata berusia 84 tahun didapatkan rerata skor daya tahan jantungparu dengan menggunakan six $m i$ nute test adalah (264 $\mathrm{m} \pm 95 \mathrm{~m})$. Penelitian tersebut menunjukkan bahwa dengan semakin bertambahnya usia terjadi penurunan kebugaran jasmani sekitar 10-20\% per dekade (Wevers \& Kwakkel, 2011). Pada penelitan ini lebih dari setengah lansia berusia antara 60-74 dengan rerata jarak tempuh yang dapat dilalui lansia selama 6 menit berjalan adalah 269,5m (pre) dan $375,5 \mathrm{~m}$ (post). Hal ini menunjukkan usia mempengaruhi kebugaran jasmani seseorang.

Oliveira \& Silveira (2013) menjelaskan faktor-faktor yang mempengaruhi kebugaran jasmani seseorang antara lain usia, jenis kelamin, Indeks Massa Tubuh (IMT) dan aktivitas fisik. Menurut laporan nasional Riskesdas tahun 2007, kurangnya aktivitas fisik paling banyak pada kelompok usia diatas 75 tahun dan berpengaruh terhadap kebugaran jasmani sebesar $76,0 \%$. Sampel dalam penelitian ini lebih dari setengahnya berusia 60-74 tahun sehingga olahraga Senam Jantung Sehat Seri-I akan berdampak lebih baik dalam meningkatkan kebugaran jasmani lansia.

Hasil penelitian lain yang dilaporkan oleh Riskesdas tahun 2013 pada kelompok usia di atas 65 tahun yang memiliki aktivitas sedenter lebih dari 6 jam sehari, dilaporkan aktivitas tersebut berpengaruh terhadap kebugaran jasmani sebesar sebesar 87,4\%. Pada kelompok usia 6574 tahun yang aktivitas fisiknya rendah, dilaporkan aktivitas fisik yang rendah berpengaruh terhadap kebugaran jasmani sebesar $58,5 \%$. Pada kelompok usia di atas 75 tahun yang memiliki gangguan muskuloskeletal, menyebabkan berkurangnya aktivitas fisik, keadaan ini berpengaruh terhadap kebugaran jasmani sebesar $85,1 \%$. Dari penelitian diatas aktivitas sedenter pada lansia menimbulkan penurunan kebugaran jasmani yang lebih besar dibandingkan lansia yang melakukan aktivitas yang kurang dan lansia yang memiliki gangguan muskkuloskeletal. Penurunan nilai kebugaran jasmani yang akan berpengaruh terhadap kualitas hidup lansia pada masa tuanya (Touhy, Jett, Ebeersole \& Hess, 2014).

Sundari, Suhadi \& Maryati (2014) mengatakan lansia sering ditemukan sindroma metabolik yang menyebabkan penyakit degeneratif. Penyakit degeneratif yang ditemukan pada lansia antara lain hipertensi, diabetes melitus dan penyakit jantung koroner. Penelitian dilakukan pada lansia penderita hipertensi (usia 6074 tahun) menggunakan one group pre test post test study design, dilaporkan terdapat pengaruh antara aktivitas fisik lansia terhadap peningkatan daya tahan jantungparu, perbaikan status gizi lansia dan penurunan tekanan darah sistolik ( $p$ $<0,05)$.

Intensitas latihan yang direkomendasikan untuk mempertahankan kesehatan lansia dan mencegah terjadinya stroke adalah intensitas sedang sedangkan untuk penyakit jantung coroner harus menggunakan intensitas latihan yang ringan (Calvin, Paula, Anne, Shirley Charlotte, Michael \& Sharon, 2010). Pada penelitian ini, intervensi berupa Senam Jantugn Sehat Seri-I merupakan olahraga aerobik intensitas sedang sehingga aman dilakukan oleh lansia. 
Fitria, N., Lidyana, L., Iskandar, S., Lubis, L., dan Purba, A. I Senam Jantung Sehat Seri-I Tiga kali seminggu meningkatkan ...

American College of Sports Medicine (2015) menjelaskan upaya untuk mencegah terjadinya penurunan kebugaran jasmani, lansia perlu melakukan aktivitas fisik/olahraga yang memenuhi kaidah Frequency, Intensity, Time, Type (FITT). Penelitian eksperimen yang telah dilakukan oleh Sundari, Suhadi, \& Maryati (2014) baru terbatas pada Senam Bugar Lansia dalam meningkatkan kebugaran jasmani. Hasil penelitian menunjukkan, berdasarkan tes jalan enam menit terjadi peningkatan daya tahan jantungparu lansia setelah melakukan Senam Bugar Lansia $(1,6255$ vs 1,6276$) \mathrm{km}$. Walaupun hasil tes ini menunjukkan kebugarannya jasmaninya masuk ke dalam kelompok kurang, namun terjadi peningkatan skor kebugaran sehingga Senam Bugar Lansia dapat meningkatkan daya tahan jantungparu bagi lansia. Berdasarkan hasil wilcoxon signed ranks test dilaporkan ada perbedaan bermakna antara daya tahan jantungparu lansia pada minggu keempat setelah Senam Bugar Lansia $(p=0,001 \quad(p<0,05)$. Pada penelitian ini Senam Jantung Sehat Seri-I dilaksanakan oleh lansia sehat selama enam minggu untuk mendapatkan efek yang baik dalam meningkatkan kebugaran jasmani.

Senam Jantung Sehat Seri-I adalah olahraga aerobik yang memiliki intensitas sedang dan berdurasi sekitar 30 menit. Olahraga senam ini tentunya sangat baik dilakukan dan aman untuk lansia. Untuk memenuhi konsep FITT, maka perlu dilakukan penelitian mengenai frekuensi yang tepat dalam meningkatkan kebugaran jasmani (daya tahan jantungparu) lansia (Ginting, 2011).

Penelitian eksperimen yang melibatkan Senam Jantung Sehat sebagian besar memberikan efek positif terhadap penurunan tekanan darah sistolik dan diastolik. Penelitian Vancafort (2016), pada penderita hipertensi sedang berusia 39 - 60 tahun (30 orang yang diberikan perlakukan Senam Jantung Sehat dengan frekuensi latihan 3 kali seminggu, takaran intensitas sedang (70-80\% DNM), durasi latihan selama 2060 menit, dan jenis latihan aerobik. Hasil penelitian menunjukkan adanya penurunan tekanan darah sistolik sebesar 3,346\% dan diastolik sebesar $4,273 \%$.
Penelitan lain yang dilakukan oleh Lalarni (2015), pada delapan orang lansia laki-laki berusia 60-65 tahun. Penelitian ini menggunakan rancangan quasi eksperimental. Hasil t-test, menunjukkan rerata tekanan darah setelah Se-

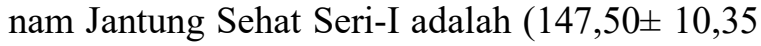
$\mathrm{mmHg}$ vs $135 / 85 \pm 11,95 \mathrm{mmHg})$. Rerata Denyut Nadi Istirahat setelah Senam Jantung Sehat Seri-I adalah $(97,88 \pm 6,24 \mathrm{mmHg}$ VS $74,13 \pm 7,81 \mathrm{mmHg})$.

Penelitian Abdul dan Cerika (2011) terhadap 15 orang lansia berusia $>60$ tahun penderita hipertensi ringan $(140-159 / 90-99 \mathrm{mmHg})$ dan 15 orang lansia penderita hipertensi sedang (160 -179/100-109 mmHg). Penelitian ini melalui pendekatan one group pre test - post test. Hasil penelitian menunjukkan Senam Jantung Sehat dapat menurunkan tekanan darah sistolik $(145,33$ vs $137,33 \mathrm{mmHg}, p=0,000(p \leq 0,05)$ dan menurunkan tekanan darah diastolik (88 $\mathrm{mmHg}$ vs $82 \mathrm{mmHg}, \mathrm{p}=0,003(p \leq 0,05)$.

Penelitian diatas menunjukkan bahwa sebagian besar Senam Jantung Sehat memberikan perubahan terhadap penurunan tekanan darah sistolik dan diastolik dan belum ditemukan penelitian mengenai pengaruh Senam Jantung Sehat dalam meningkatkan derajat kebugaran jasmani (daya tahan jantungparu) pada lansia, oleh karena itu sangat penting dilakukan penelitian mengenai Senam Jantung Sehat Seri-I terhadap kebugaran jasmani dengan frekuensi tepat.

Senam Jantung Sehat Seri-I memiliki pola gerak senam yang khas. Kemungkinan pola gerak Senam yang dapat meningkatkan fungsi jantungparu yaitu gerakan I, IV, VI, VII, VIII, IX, X, XII, XIV, XV, XVI, XVII, XVIII, XIX, dan gerakan $X X$. Gerakan senam jantung sehat tersebut pada umumnya berupa jalan ditempat dengan menggerakkan tangan, menepuk tangan di atas kepala, merentangkan tangan ke depan, ke atas dan menarik nafas (Ginting,2011).

Senam jantung sehat memiliki tiga prinsip gerakan yaitu pemanasan, inti dan pendinginan. Prinsip gerakan pemanasan bertujuan untuk melemaskan otot-otot tubuh. Tanda-tanda bahwa seseorang sudah berhasil melakukan pemanasan adalah detak jantung meningkat, suhu tubuh 
Fitria, N., Lidyana, L., Iskandar, S., Lubis, L., dan Purba, A. | Senam Jantung Sehat Seri-I Tiga kali seminggu meningkatkan ...

meningkat 1-2 derajat celcius, dan badan berkeringat. Gerakan pemanasan ini penting untuk mengurangi risiko cedera dan kelelahan (Ginting,2011).

Prinsip gerakan kedua adalah gerakan inti. Tujuan gerakan inti sesuai dengan jenis olahraga kebugaran yang diinginkan. Senam jantung sehat ditujukkan untuk meningkatkan daya kerja jantung. Latihan dilakukan 20 menit atau disesuaikan dengan tujuan latihan (Ginting,2011)

Prinsip gerakan ketiga adalah gerakan pendinginan. Tahap pendinginan bertujuan untuk mengembalikan keadaan tubuh seperti semula. Gerakan yang dapat dilakukan tahap pendinginan adalah berdiri sambil menggerak-gerakkan kaki, berjalan di tempat, atau gerakan-gerakan ringan yang lainnya. Tahapan ini berlangsung selama 5 menit (Ginting,2011)

Pada saat terjadinya proses aging, volume mitokondria, isi kolagen dan kelentukan sendi mengalami penurunan. Meniscus dan kartilago articular mengalami penurunan fungsi sehingga resiko terjadinya injuri sebesar $20 \%$ khususnya pada ekstremitas bawah. Selain itu terjadi mikrotrauma dan kekurangan oksigen pada vaskularisasi di sekitar tendon sehingga tendon mengalami peradangan yang berakibat terhadap penurunan energi aerobik pada sistem musculoskeletal (Darmojo, 2014)

Penurunan energi aerobik secara fisiologis pada lansia memerlukan upaya yang tepat untuk lansia dalam berolahraga. Olahraga yang aman untuk lansia berupa aerobik, berintensitas sedang, tidak boleh menyebabkan stres pada bagian orthopedik, dan tidak boleh lebih dari 150 menit/minggu (Banerjee, Jadhav, \& Bhawwkar, 2012).

Untuk meningkatkan daya tahan jantungparu pada lansia dapat dilakukan latihan sebanyak 3-5 kali/minggu dengan intensitas latihan ringan dan sedang (intensitas ringan: $50-60 \%$ Denyut Nadi Maksimal (DNM), intensitas sedang 60-75\% DNM. Waktu yang diperlukan setiap melaksanakan latihan selama 20-60 menit/ latihan dengan tipe latihan aerobik. Hasil latihan akan meningkatkan daya tahan jantungparu setelah 6-12 minggu dan kondisi daya tahan jantungparu akan stabil selama 20 minggu (Ralph,
Klippel, John, Koopman, \& William, 2013). Pendapat lain menurut WHO dalam Harber \& Scoot (2009), lansia dapat melakukan olahraga aerobik dengan intensitas sedang yang dilakukan selama 30 menit dengan frekuensi $5 \mathrm{x} /$ minggu.

Harber \& Scoot (2009) mengatakan olahraga merupakan aktifitas fisik yang ditandai dengan kemampuan bergerak sesuai dengan tujuan olahraga. Kemampuan bergerak pada lansia dapat diukur dengan alat accelerometer/ pedometer. Salah satu indikator untuk melihat kemampuan bergerak lansia adalah jumlah langkah yang biasa ditempuh lansia per hari. Lansia sehat rata-rata mampu melangkah sebanyak 2000-9000 langkah/hari. Olahraga yang dilakukan dengan intensitas sedang (10 menit-150 menit/minggu) setara dengan 5000 langkah/hari oleh karena itu kemampuan melangkah yang tepat dilakukan lansia berada pada intensitas latihan sedang.

Darmojo (2014) menjelaskan olahraga adalah suatu bentuk kegiatan fisik yang dapat meningkatkan kesegaran jasmani, karena dalam olahraga tidak hanya melibatkan sistem musculoskeletal semata namun juga mengikutsertakan sistem lain seperti sistem kardiovaskuler, sistem respirasi, sistem ekskresi, sistem saraf. Olahraga atau latihan fisik berdasarkan pemakaian oksigen atau sistem energi dominan yang digunakan dalam suatu latihan terbagi menjadi dua bagian yaitu olahraga aerobik dan anaerobik.

Perbedaan utama antara olahraga aerobik dan anaerobik terletak pada keterlibatan oksigen dalam memproduksi energi. Olahraga aerobik adalah olahraga yang dilakukan secara terus menerus dan kebutuhan oksigen masih dapat dipenuhi oleh tubuh. Sebagai contoh yang termasuk olahraga aerobik yaitu jogging. Saat melakukan jogging kebutuhan oksigen masih dapat dipenuhi oleh tubuh, karena jogging tidak memerlukan kecepatan dan termasuk olahraga yang intensitasnya rendah dan terjadinya penumpukan asam laktat lebih lama waktunya (Darmojo,2014).

Darmojo (2014) menjelaskan olahraga anaerobik yaitu olahraga dengan kebutuhan oksi- 
gennya tidak dapat dipenuhi oleh tubuh. Hal ini terjadi ketika kebutuhan energi di dalam tubuh melebihi yang telah disediakan oleh pernapasan sehingga tubuh dipaksa bekerja tanpa oksigen. Sebagai contoh yang termasuk olahraga jenis anaerobik yaitu lari sprint $100 \mathrm{~m}$ karena olahraga tersebut membutuhkan kecepatan sehingga daya tahan tubuh cepat berkurang dan penumpukan asam laktat lebih cepat terjadi.

Pada saat terjadinya olahraga menurut Harber \& Scoot (2009), terjadi adaptasi fisiologi terhadap kerja fisik. Adaptasi fisiologi terdiri dari adaptasi akut dan kronik. Adaptasi akut merupakan penyesuaian tubuh dalam waktu segera saat aktifitas kerja dilakukan. Adaptasi kronik merupakan hasil perubahan pada tubuh oleh suatu periode program latihan fisik tertentu. Adanya kerja fisik menyebabkan beban bagi tubuh dan hal ini akan mengakibatkan mekanisme penyesuaian dari organ tubuh. Penyesuaian ini tergantung kepada usia, suhu lingkungan, berat ringan beban, lamanya, cara melakukan, dan jumlah organ yang terlibat selama kerja fisik.

Adaptasi akut pada kondisi olahraga merupakan penyesuaian tubuh segera saat berolahraga. Adaptasi kronik pada kondisi olahraga merupakan hasil perubahan pada tubuh setelah dilakukan program latihan fisik yang dilakukan secara terprogram dan terencana dan memenuhi kaidah FITT (Harber \& Scoot, 2009) .

Setelah kegiatan olahraga terjadi adaptasi akut dan kronis pada sistem vaskuler (Sebastianus, 2014). Perubahan akut yang terjadi berupa perubahan frekuensi denyut jantung, volume darah sekuncup (stroke volume) dan curah jantung (Cardiac Output), tekanan darah, dan suplai darah. Curah jantung meningkat setelah olahraga dari $5900 \mathrm{cc}$ menjadi $24000 \mathrm{cc}$, aliran darah ke jantung meningkat setelah olahraga daru $250 \mathrm{cc}$ menjadi $1000 \mathrm{cc}$, suplai darah ke otot rangka meningkat setelah olahraga $650 \mathrm{cc}$ menjadi 28.250cc (Aaronson, Philip, Jeremy, \& Ward, 2010).

Selain terjadinya peningkatan frekuensi denyut jantung, volume darah sekuncup (stroke volume) dan curah jantung (cardiac output), tekanan darah, dan suplai darah terjadi pening- katan aktivitas simpatis pada nodus SA yang menyebabkan kecepatan/frekuensi denyut jantung meningkat. Semakin tinggi intensitas latihan, maka denyut jantung akan semakin cepat (Kerling et al., 2015).

Berdasarkan teori ambang batas anaerobik (anaerobic threshold), jika intensitas latihan dinaikan, maka frekuensi denyut jantung juga akan naik, tetapi jika intensitas terus dinaikan pada suatu saat hubungannya tidak liner lagi (berbentuk garis lurus) melainkan akan melengkung. Peningkatan frekuensi denyut jantung yang saat intensitas dinaikkan, tidak akan meningkatkan curah jantung (Kerling et al., 2015).

Setelah 160 kali per-menit bagi yang tidak terlatih atau 180 kali per-menit bagi yang terlatih, maka denyut jantung akan mengalami floater, sehingga stroke volume akan berkurang dan Cardiac Output menurun (Kerling et al., 2015).

Frekuensi denyut jantung maksimal ditentukan dengan rumus 220 dikurangi umur. Cardiac Output pada intensitas $100 \%$ tidak berbeda banyak dengan curah jantung pada intensitas 90\% (Sebastianus, 2014). Sesuai dengan teori diatas, Senam Jantung Sehat Seri-I frekuensi $3 \mathrm{x} /$ minggu dengan intensitas sedang dapat meningkatkan frekuensi denyut jantung dan stroke volume sehingga Cardiac Output akan meningkat sehingga daya tahan jantungparu akan meningkat. Apabila Senam Jantung Sehat Seri-I dilakukan dalam frekuensi empat kali seminggu dan lima kali seminggu tidak memberikan efek peningkatan cardiac output karena jantung mengalami overtraining atau beban latihan yang berlebihan.

Overtraining dapat dilihat dari respon seseorang yang telah melakukan latihan yang rutin dalam waktu yang sudah lama, namun merasa kemajuannya sangat lambat. Lambatnya kemajuan dari seseorang dapat dilihat dari tidak adanya adaptasi pada organ tubuh yang kita inginkan dari efek olahraga yang kita harapkan (Sebastianus, 2014).

Sebastianus (2014) mengatakan pada prinsipnya setiap latihan selalu mengakibatkan cedera atau penyesuaian mikrotrauma (adaptive mi- 
crotrauma). Adaptive mikrotrauma pada tubuh ini akan menghasilkan cytokine. Zat ini menjadi alarm awal seseorang mengalami overtraining setelah olahraga. Overtraining juga menyebabkan produksi radikal bebas yang berlebihan. Radikal bebas ini dapat merusak sel tubuh dan membuka pintu masuk penyakit jantung, kanker, penuaan dini dan penurunan sistem kekebalan tubuh oleh karena itu penting sekali kita harus menentukan frekuensi olahraga yang tepat bagi lansia sehingga tidak menimbulkan overtraining, peningkatan radikal bebas. Apabila kondisi tersebut dapat diatasi maka penyakit jantung, kanker, penuaan dini dan penurunan sistem kekebalan tubuh tidak akan terjadi pada lansia dan lansia dapat hidup lebih produktif serta berkualitas hidupnya.

Olahraga selain meningkatkan frekuensi denyut jantung dan stroke volume serta Cardiac Output, olahraga dapat menyebabkan vasokontriksi vena yang diinduksi oleh saraf simpatis serta peningkatan aktivitas pompa otot rangka dan pompa respirasi sehingga menyebabkan venous retun meningkat. (Aaronson, Philip, Jeremy\&Ward,2010).

Peningkatan venous return melalui mekanisme Frank-Starling dan peningkatan kontraktilitas miokardium yang distimulasi oleh saraf simpatis menyebabkan stroke volume jantung semakin meningkat. Peningkatan stoke volume dan frekuensi denyut jantung akan meningkatkan Cardiac Output semakin meningkat (Aaronson, Philip, Jeremy \& Ward, 2010).

Peningkatan Cardiac Output yang lebih besar dari resistensi perifer total menyebabkan peningkatan tekanan darah arteri. Vasodilatasi arteriol yang dikontrol secara lokal, yang diperkuat oleh efek vasodilatasi epinefrin menyebabkan aliran darah ke otot jantung dan otot rangka yang aktif semakin meningkat sedangkan aliran darah ke otak tetap stabil karena stimulasi saraf simpatis tidak berefek pada arteriol yang ada di otak. (Aaronson, Philip, Jeremy \& Ward, 2010).

Aliran darah ke otot rangka yang aktif yang meningkat menyebabkan pusat kontrol hipotalamus menginduksi arteriol kulit sehingga terjadi peningkatan aliran darah di kulit dan me- nimbulkan panas pada permukaan kulit. Peningkatan stroke volume maupun Cardiac Output akan diikuti dengan bertambahnya pembuluh darah pada otot jantung, sehingga aliran darah pada otot berjalan dengan lancar. Banyaknya pembuluh darah pada otot jantung, akan saling menggantikan apabila ada satu atau beberapa pembuluh darah lain yang tersumbat (Aaronson, Philip, Jeremy \& Ward, 2010).

Senam Jantung Sehat Seri-I frekuensi tiga kali seminggu dengan intensitas sedang menyebabkan terjadinya peningkatan daya tahan jantungparu karena frekuensi yang tepat akan menyebabkan peningkatan frekuensi jantung dan stroke volume sehingga Cardiac Output menjadi meningkat. Prijo (2011) menjelaskan bahwa peningkatan Cardiac Output akan meningkatkan suplai oksigen ke otot rangka yang aktif sehingga venous return juga menjadi meningkat dan menambah pertumbuhan pembuluh darah di sekitar otot jantung (neovaskularisasi) sehingga miokardium semakin kuat dalam berkontraksi dan mempengaruhi daya tahan jantung paru.

Pada lansia yang rutin melakukan senam jantung sehat seri-I, kondisi pembuluh darah lansia saat senam mengalami vasodilatasi dan peningkatan elastisitas sehingga memperlancar pengiriman nutrisi dan oksigen.

Olahraga juga dapat meningkatkan diameter pembuluh darah, penurunan rasio tebal tunika intima-media serta pembesaran pembuluh darah secara tetap (Cornelissen, \& Neil, 2013).

Dalam penelitian Colberg, Sigal, \& Ronald (2010), olahraga selain menyebabkan adaptasi akut pada sistem vaskuler, terjadi juga adaptasi kronis. Salah satu perubahan yang terjadi akibat adaptasi kronis adalah pembesaran ruang jantung, peningkatan elastisitas pembuluh darah, perbaikan kontrol metabolisme berupa perbaikan level glukosa dalam darah dan resistensi insulin, perbaikan fungsi ginjal dan penurunan tekanan darah.

Senam Jantung Sehat Seri-I frekuensi tiga kali seminggu dapat menstimulasi pembesaran ruang jantung, peningkatan elastisitas pembuluh darah, perbaikan kontrol metabolisme, perbaikan fungsi ginjal, penurunan tekanan darah. Hal ini menunjukkan bahwa Senam ini selain dapat 
meningkatkan daya tahan jantung paru, sistem GIT dan urinari juga menjadi lebih baik proses metabolismenya sehingga fungsi sistem tersebut akan meningkat.

Colberg, Sigal, \& Ronald. (2010) menjelaskan kondisi kebutuhan suplai oksigen ke otot rangka tidak maksimal saat berolahraga akan terjadi penumpukan metabolit dan merangsang saraf sensorik dalam otot. Aktivasi saraf sensorik ini akan mestimulasi kemoreseptor dari saraf mekanoreseptor otot yang meningkatkan aktivitas saraf simpatik untuk meningkatkan tekanan arteri.

Kemoreseptor berfungsi untuk merespons perubahan konsentrasi $\mathrm{O} 2$ dan $\mathrm{CO} 2$ serta bertanggungjawab dalam meningkatkan ventilasi paru-paru. Terdapat dua kemoreseptor yaitu sentral kemoreseptor di otak (permukaan ventral spinal cord ) dan peripheral kemoreseptor (antara carotid dan badan aortic) (Colberg, Sigal, \& Ronald, 2010).

Peripheral kemoreseptor menghubungkan pusat pernafasan di medula oblongata dan nukleus jalur terkecil, dan berespon terhadap keadaan hipoksia (Guimaraes, Belli, Juliana, \& Bacal, 2009). Saat reseptor ini merasakan ada peningkatan produksi $\mathrm{CO} 2$ dan kekurangan $\mathrm{O} 2$, peripheral kemoreseptor akan menstimulasi otot pernafasan melalui chemoreflex (Kerling et al,2015).

Perbaikan pada fungsi ginjal juga merupakan salah satu adaptasi kronis yang terjadi saat berolahraga dengan tepat dan teratur. Ginjal berfungsi dalam pengaturan sodium plasma sehingga akan membantu dalam proses pengaturan plasma dan cardic output. Hal ini sangat membantu dalam penurunan tekanan darah pada penderita hipertensi (Prijo,2011).

Kenney, Larry, Wilmore, Jack, Costill, \& David, (2011) menjelaskan pada saat olahraga, sistem saraf otonom khususnya sistem saraf simpatis dan sistem saraf parasimpatis berperan penting dalam tubuh selama olahraga. Sistem saraf simpatis disebut sebagai sistem fight-orflight, menyiapkan tubuh untuk menghadapi krisis dan menopang atau menjaga fungsinya selama krisis. Saraf simpatis berpengaruh pada pening peningkatan denyut jantung dan kekuatan jantung, dilatasi pembuluh koroner, meningkatkan suplai darah ke otot jantung, meningkatkan vasoldilatasi periferal aliran darah menuju otot rangka yang aktif, vasokontriksi menuju sebagian besar jaringan untuk mencegah darah mengalirinya dan mengalihkannya ke otot yang aktif, meningkatkan tekanan darah, memberikan perfusi otot, dan memperbaiki aliran darah vena menuju jantung (Kenney, Larry, Wilmore, Jack, Costill, \& David, (2011)

Saraf otonom berupa saraf simpatis menstimulasi medula adrenalin pada untuk mengeluarkan hormon epinefrin dan noreprinefrin (sirkulasi katekolamin). Sirkulasi katekolamin dapat memberikan efek peningkatan frekuensi denyut jantung dan kontraksi tambahan, laju metabolisme, glikogenesis,pelepasan glukosa dalam darah, tekanan darah dan respirasi serta redistribusi darah pada otot rangka yang aktif (Kenney, Larry, Wilmore, Jack, Costill, \& David, 2011).

Sistem saraf otonom berpusat di hipotalamus, medula oblongata, dan saraf tulang belakang. Saraf parasimpatis berhubungan langsung pada medula oblongata, sedangkan saraf simpatis berhubungan dengan saraf tulang belakang. Kedua saraf otonom ini bercabang dengan Sino Atrial node (SA) dan atrioventricular valve node (AV). Nodus ini akan dipengaruhi oleh saraf simpatis dan parasimpatis untuk mengontrol denyut jantung (Kenney, Larry, Wilmore, Jack, Costill, \& David, 2011)

Saat cabang-cabang saraf simpatis dan parasimpatis terstimulasi, hormon norepinefrin dikeluarkan, menyebabkan peningkatan pada denyut jantung dan peningkatan pada kontraksi ventrikel. Parasimpatis yang mempersarafi jantung dari saraf vagus dan dikontrol oleh pusat vasomotor (Kenney, Larry, Wilmore, Jack, Costill, \& David, 2011).

Meningkatnya hormon epinefrin saat olahraga menyebabkan semakin kuatnya kontraksi otot jantung. Meskipun demikian, tekanan sistolik tidak langsung meninggi karena pengaruh epinefrin pada pembuluh darah dapat menyebabkan vasodilatasi (Sebastianus, 2014). Peningkatan signifikan tekanan sistolik dan nadi, 
disebabkan oleh ejeksi darah oleh ventrikel kiri secara lebih cepat dan kuat, yang menyebabkan suatu peningkatan rata-rata tekanan darah arterial (Aaronson, Philip, Jeremy, \& Ward, 2010).

Efek penurunan tekanan (sistolik) darah setelah olahraga, mulai terlihat pada 1-3 jam setelah melakukan olahraga selama 30-45 menit. Efek penurunan darah ini akan terjadi lebih dari 9 jam setelah olahraga. Penurunan tekanan darah yang menetap akan lebih terlihat setelah $4-6$ minggu latihan (Lucifora, 2015). Penelitian ini dilakukan selama enam minggu sehingga lansia yang hipertensi yang melakukan Senam Jantung Sehat Seri-I juga mengalami penurunan tekanan darah. Penurunan tekanan darah diastolik setelah olahraga berhubungan dengan durasi, yaitu lamanya latihan yang dilakukan (Kenney, Larry, W., Wilmore, Jack, Costill, \& David, 2011).

Pada saat berlatih, suplai darah mengalir ke otot-otot yang terlibat dalam gerak. Darah akan mencukupi kebutuhan latihan seperti lemak dan gula untuk penyediaan energi dan membawa sisa -sisa metabolisme seperti air dan $\mathrm{CO}_{2}$. Semakin tinggi intensitas latihan, suplai darah yang ke otot akan semakin banyak. Hal ini lansia sehat yang melakukan Senam Jantung Sehat Seri-I frekuensi $3 \mathrm{x} /$ minggu dengan intensitas sedang menyebabkan suplai darah ke otot yang digerakkan semakin besar.

Cornelissen \& Neil (2013) mengatakan tekanan darah pada hipertensi akan menurun diakibatkan adanya perbaikan faktor-faktor yang memengaruhi tekanan darah antara lain: peningkatan elastisitas pembuluh darah, semakin optimalnya kerja jantung (cardiac output), menurunnya tahanan perifer akibat peningkatnya diameter pembuluh darah, menurunnya viskositas darah, dan terkontrolnya volume darah.

Penurunan pembuluh darah perifer setelah melakukan olahraga menyebabkan diameter pembuluh darah bertambah, diakibatkan karena menurunnya pengaruh saraf simpatis atau bertambahnya pengaruh vasodilator lokal seperti nitric oxide. Faktor lain penyebab penurunan tekanan darah akibat olahraga adalah penurunan norepinefrin plasma darah yang berhubungan dengan vasodilatasi pembuluh darah dan perbaikan fungsi ginjal (Cornelissen \& Neil, 2013).
Prijo (2011) menjelaskan bahwa olahraga sebaiknya dilakukan sesuai dengan kemampuan tubuh dalam menanggapi stress. Bila tubuh diberi beban latihan yang terlalu ringan maka tidak akan terjadi proses adaptasi. Sebaliknya, jika diberikan latihan yang terlalu berat dan tubuh tidak dapat mentolerir,akan menyebabkan terganggunya proses homeostatis pada sistem tubuh dan dapat mengakibatkan kerusakan pada jaringan. Senam Jantung Sehat Seri-I yang dilakukan lansia sehat dengan frekuensi empat kali seminggu dan lima kali seminggu dianggap memiliki beban latihan yang besar bagi tubuh sehingga tidak memberikan efek terhadap sistem tubuh bahkan dapat menimbulkan kerusakan jaringan sehingga homeostatis tubuh terganggu.

Olahraga juga akan mempengaruhi sistem pernafasan. Olahraga mempengaruhi kadar $\mathrm{O}_{2}$ dan $\mathrm{CO}_{2}$. Kadar $\mathrm{O}_{2}$ dalam jumlah yang besar akan berdifusi dari alveoli ke dalam darah vena kembali ke paru-paru. Sebaliknya, kadar $\mathrm{CO}_{2}$ masuk dari darah ke dalam alveoli. Oleh karena itu proses ventilasi akan meningkat untuk mempertahankan konsentrasi gas alveolar sehingga terjadi peningkatan pertukaran $\mathrm{O}_{2}$ dan $\mathrm{CO}_{2}$ (Prijo, 2011).

Sebelum olahraga, umpan balik proprioseptif dari otot rangka dan sendi aktif menyebabkan korteks motor menjadi lebih aktif dan mengirimkan impuls ke pusat inspirasi sehingga respirasi bertahap meningkat. Saat awal mula gerakan tubuh, terjadi peningkatan inspirasi dan kedalaman serta tingkat pernapasan (Prijo, 2011).

Prijo (2011) menjelaskan pada saat olahraga berlangsung, terjadi peningkatan metabolisme pada otot sehingga menimbulkan panas, peningkatan $\mathrm{CO}_{2}$ dan $\mathrm{H}^{+}$. Semua faktor tersebut akan meningkatkan penggunaan oksigen dalam otot dan oksigen di arteri akibatnya, lebih banyak $\mathrm{CO}_{2}$ dan $\mathrm{H}^{+}$dalam darah. Kondisi tersebut menyebabkan kemoreseptor merangsang pusat inspirasi, sehingga terjadi peningkatan kedalaman pernapasan. Senam Jantung Sehat Seri-I frekuensi tiga kali seminggu selain berefek terhadap penurunan tekanan darah pada sistem kardiovaskuler, memberikan pengaruh positif juga terhadap sistem respirasi dan urinaria sehingga 
Fitria, N., Lidyana, L., Iskandar, S., Lubis, L., dan Purba, A. I Senam Jantung Sehat Seri-I Tiga kali seminggu meningkatkan ...

mempengaruhi homeostasis dalam tubuh menjadi optimal.

\section{SIMPULAN}

Senam Jantung Sehat Seri-I frekuensi 3 kali seminggu dapat meningkatkan kebugaran jasmani (daya tahan jantungparu) pada lansia. Hasil penelitian ini menjadi dasar bagi peneliti selanjutnya untuk meneliti frekuensi dari cabang olahraga lain yang aman untuk dilakukan lansia. Bagi PRSLU dan PMP UPTD Ciparay dapat menggunakan Senam Jantung Sehat Seri-I frekuensi 3 kali seminggu sebagai program rutin bagi lansia sehat dan dapat mengevaluasi peningkatan kebugaran jasmaninya.

\section{DAFTAR PUSTAKA}

Aaronson, Philip, I., Jeremy, \& Ward, P. T. (2010). At Glance : Sistem Kardiovaskuler (Terjemahan). Jakarta: Penerbit Erlangga.

Abdul, A., \& Cerika, R. (2011). Pengaruh Olahraga Terprogram Terhadap Tekanan Darah dan Daya Tahan Kardiorespirasi pada Atlet Pelatda Sleman Cabang Tenis Lapangan. Yogyakarta: FIK UNY.

American College of Sports Medicine. (2015). ACSM's resource manual for guidelines for exercise testing and prescription. 7th edition. American College of Sports Medicine.

Banerjee, A., Jadhav, S. L., \& Bhawwkar, J. S. (2012). Limitation of Activities in Patients with Musculoskeletal dissorders. Ann Med Health Sciences Research, 2(1), hlm. 5-9.

Calvin, H. H., Paula, D., Anne, B. N., Shirley, A. G., Charlotte, P., Michael, D. L., \& Sharon, A. J. (2010). Physical Activity and Years of Healthy Life in Older Adults: Results From the Cardiovascular Health Study. J Aging Phys, 18(3), hlm. 313-334.

Chung, W., Baguet, A., Bex, T., Bishop, D. J., \& Derave, W. (2014). International Journal of Sport Nutrition and Exercise Metabolism. 24 (3), hlm. 315-324.

Colberg, S., Sigal, \& Ronald. (2010). Exercise and Type 2 Diabetes. Diabetes care, 33, hlm. 12.

\section{UCAPAN TERIMA KASIH}

Ucapan terima kasih kepada Universitas Padjadjaran yang telah memberikan kesempatan peneliti untuk melakukan pendidikan Doktor. Selain itu kepada kepala panti dan instruktur senam, perawat panti serta lansia yang mendukung proses penelitian ini.

Penelitian ini merupakan hasil kontribusi dari semua pihak yang mendukung terhadap proses pengumpulan data, analisis data, interpretasi data dan pembuatan artikel ilmiah untuk dipublikasikan.

Cornelissen, V. A., \& Neil, A. (2013). Exercise Training for Blood Pressure : A systematic Review and Meta- analysis. Journal of The American Heart Association, 2(1). Retrieved fromhttps://doi.org/10.1161/

JAHA.112.004473

Darmojo, B. (2014). Buku Ajar BoedhiDarmojo Geriatri (Ilmu Kesehatan Usia Lanjut), 5. Jakarta: Badan Penerbit FKUI.

Gorska-Ciebiada, M., Saryusz-Wolska, M., Borkowska, A., \& Loba, J. (2015). Serum levels of inflammatory markers in depressed elderly patients with diabetes and mild cognitive impairment. PLoS One (Internet), 10 (3), hlm. 1-17. Retrieved fromhttp:// dx.doi.org/10.1371/journal.pone.0120433

Ginting, S. U. (2011). Teknik Senam Jantung Sehat Untuk Meningkatkan Daya Tahan Jantung pada Peserta Senam Jantung Sehat Lansia di Kota Medan. Jurnal Pengabdian Kepada Masyarakat, 17(66).

Harber, P. M., \& Scoot, T. (2009). Aerobic Exercise Training Improves Wholemuscle and Single Myofiber Size and Functions in Older Women. Journal Physical Reguler Integral Company Physical, 10, hlm. 11-42.

Kemenkes RI. (2016). Situasi dan Analisa Lanjut Usia. Jakarta Selatan.

Kenney, Larry, W., Wilmore, Jack, H., Costill, \& David, L. (2011). Physiology of Sport and 
Fitria, N., Lidyana, L., Iskandar, S., Lubis, L., dan Purba, A. | Senam Jantung Sehat Seri-I Tiga kali seminggu meningkatkan ...

Exercise (5th ed). USA: Human Kinetics.

Kerling A, Tegtbur U, Gützlaff E, Kück M, Borchert L, Ates Z, et al. (2015). Effects of adjunctive exercise on physiological and psychological parameters in depression: a randomized pilot trial. J Affect Disord 177:1 -6. doi:10.1016/j. jad.2015.01.006

Lalarni, H. K. (2015). Pengaruh Senam Jantung Sehat Seri V terhadap Kebugaran dan Lemak Tubuh pada Anggota Posyandu Lansia Amrih Sehat Kec. Bergas Semarang.

Lucifora, C. (2015). Performance-related pay and labor productivity (IZA World of Labor). Universita Cattolica, Italy, IZA, and Germany. doi : 10.15185/izawol.152

Martinson, M., \& Berridge, C. (2015). Successful aging and its discontents: A systematic review of the social gerontology literature. Gerontologist, 55(1), hlm. 58-69.

Oliveira, N., \& Silveira, H. (2013). Assesment of cardiorespiratory fitness using submaximal protocol in older adults. Review Psiq Clinic, 40, hlm. 88-92.

Pescatello, L. S., Arena, R., Riebe, D., Thomson, P. D., Willian, L., \& Wilkins (2014). ACSM's Guidelines for Exercise Testing and Precription (9th ed). Journal of the Canadian Chiripractic Association, 58(3). hlm. 328.
Prijo, S. (2011). Peran Latihan Fisik dalam Pencegahan, Pengontrolan, serta Pengobatan Hipertensu. Jurnal Medikora, 7(2).

Ralph, M. D., Klippel, John, H. M., Koopman, \& William, J. M. (2013). Osteoarthritis, Epidemiology, Pathology, and Pathogenesis. In : Primer on the Rheumatic Diseases (10th ed). Atlanta: Arthritis Foundation.

Sebastianus, P. (2014). Fisiologi Latihan. Retrieved Januari 28, 2014, diunduh dari http:// staff.uny.ac.id/sites/../Drs../Fisiologi\% 20Latihan.pdf.

Sundari, M. J., Suhadi, \& Maryati. (2014). Pengaruh Senam Lansia terhadap Penurunan Tekanan Darah Lansia di Panti Wreda Usia Bethany Semarang.

Touhy, T. A., Jett, K. F., Ebeersole, \& Hess. (2014). Gerontological Nursing and Healthy Aging. Missouri : Elseiver Mosby.

Wevers, L. E., \& Kwakkel, G. (2011). "Is outdoor use of the six-minute walk the test with a global positioning system in stroke patients own neighbourhoods reproducible and valid?". J Rehabil Med, 43(11), hlm. 10271031. 